\title{
Governança metropolitana e política de saneamento: trajetórias dependentes na Grande São Paulo*
}

\author{
Metropolitan governance and sanitation policy: \\ path dependences in Greater São Paulo
}

Marcelo Aversa [I]

Vanessa Elias de Oliveira [II]

\begin{abstract}
Resumo
Este artigo aplica os conceitos de path dependence e critical juncture às relações intergovernamentais, estabelecidas concretamente entre municípios e estado no processo de metropolização de São Paulo (década de 1940), como metodologia de análise institucional histórica dos serviços de saneamento da Grande São Paulo. Da análise das legislações municipais e estadual, constatou-se o desenvolvimento institucional histórico da Sabesp e o processo de consolidação da trajetória dependente da prestação interdependente dos serviços de saneamento entre operadoras municipais (distribuição local) e estaduais (produção regional) durante 0 processo de metropolização da Grande São Paulo. Essa trajetória institucional dependente permanece até os dias de hoje na Região Metropolitana de São Paulo, como origem de conflitos judiciais por meio dos quais a Sabesp vem ampliando a sua atuação nos municípios metropolitanos.
\end{abstract}

Palavras-chave: governança metropolitana, política de saneamento, relações intergovernamentais, autonomia municipal, dependência de trajetória.

\begin{abstract}
This paper applies the concepts of path dependence and critical juncture to intergovernmental relations established between municipalities and the state in the metropolization process of São Paulo (1940s), as a methodology of historical institutional analysis of sanitation utilities in the Greater São Paulo area. From the analysis of municipal and state legislations, we verified the historical institutional development of Sabesp and the consolidation process of the path dependence of the interdependent provision of sanitation services between municipal (local) and state (regional) operators during the Greater São Paulo metropolization process. This institutional path dependence remains nowadays in the Metropolitan Region of São Paulo, as a source of legal conflicts through which Sabesp has been expanding its operations in metropolitan municipalities.
\end{abstract}

Keywords: metropolitan governance; sanitation policy; intergovernmental relations; municipal autonomy; path dependence. 


\section{Introdução}

Uma importante questão do saneamento metropolitano na federação brasileira reside nos conflitos entre operadores municipais e estaduais dos serviços de abastecimento de água e esgotamento sanitário (saaes) ${ }^{1}$. Porque nossa federação se consolidou de forma trina, processos de centralização e descentralização federativas e de conformação dos arranjos institucionais de governança metropolitana também são muito peculiares. 0 pacto federativo pode estabilizar as bases de interação entre os entes federativos e destes com a sociedade, tornando as relações intergovernamentais (RIGs) mais cooperativas e menos competitivas. Essas mudanças institucionais, mesmo que lentamente, vêm ocorrendo na história recente brasileira. Se conflitos persistem, a questão, então, não é meramente de estabelecimento das regras do jogo, mas também de quando e de como ocorrem as mudanças institucionais (Pierson, 2004, p. 64; Thelen, 2000).

0 problema deste artigo é discutir a reconstituição histórica dos arranjos federativos entre serviços municipais e estaduais da qual emergiu a forma interdependente de prestação dos saaes. Essa forma de RIG, formulada nas décadas de 1940 e 1950, apresentou-se como solução para a cooperação federativa na implementação da política de saneamento supramunicipal e, na atualidade, é a base de conflitos judiciais entre os poucos serviços municipais de saneamento existentes da Região Metropolitana de São Paulo (RMSP) e a Companhia de Saneamento Básico do Estado de São Paulo (Sabesp) (Sabesp, 2019, pp. 23-24). Em outras palavras, trata-se de discutir quais instituições e organizações e quando e como estas estabeleceram os arranjos institucionais pelos quais couberam, aos serviços municipais, operação de distribuição de água potável e coleta de esgoto no âmbito local e, para os serviços estaduais, coube a produção de água a grosso destinada a atender aos municípios, assim como, a coleta e o tratamento de esgoto em âmbito regional. A literatura institucionalista histórica adotada por este artigo possibilita uma análise política e histórica das instituições num horizonte temporal de longa duração, percorrendo da estruturação da Grande São Paulo na década de 1940 até a entrada em vigência da Lei Nacional de Saneamento Básico (lei federal n. 11.445, de 5 de janeiro de 2007 - LNSB). Isto porque a prestação de serviços de saneamento interdependente consiste na path dependency de arranjo institucional interfederativo para implementação de políticas de saneamento em âmbito regional, uma vez que foi adotada reiteradamente (feedback positivo) desde a década de 1940 na Grande São Paulo até o presente momento, conforme estabelecido no artigo 12 da LNSB. ${ }^{2}$ Em suma, este artigo pretende responder à seguinte questão: como a prestação interdependente de serviços de saneamento se consolida como trajetória dependente para a constituição de arranjos federativos voltados à implementação de políticas de saneamento supramunicipais na Grande São Paulo?

O neoinstitucionalismo histórico de Paul Pierson (2004) é assumido como lente teórica para compreender as trajetórias institucionais dos serviços de saneamento e seus efeitos para as relações intergovernamentais na RMSP. A aplicação dos conceitos institucionalistas históricos pressupõe um passo além de uma compreensão trivial da importância das instituições, à medida que se produza 
uma análise sobre "quais instituições de fato afetam comportamentos e decisões, e como, isto é, por meio de que processos e mecanismos" (Arretche, 2007, p. 149, grifos da autora). Acrescentando-se as categorias tempo e sequência dos processos, o institucionalismo histórico de Pierson amplia a capacidade de análise para identificar regularidades e relações de causalidade, no sentido de compreender como as preferências dos atores são formadas pelo ambiente institucional de interação (Lima et al., 2016, p. 111, apud Pierson, 2004, p. 54). Na literatura internacional, a aplicação dessa abordagem se inicia na década de 1990 (Collier e Collier, 1991; Steinmo, Thelen e Longstreth, 1992). No Brasil, pesquisas realizadas por meio desta abordagem e referências vêm se ampliando a partir da década de 2000 (Souza, 2003; Menicucci, 2009; Gomide, 2011; Leão, 2013; Fernandes e Wilson, 2013; De Sousa e Costa, 2016; Aversa, 2016; Bujak, 2018).

Essa narrativa histórica dos fatos, cujo método foi baseado em análises documentais, descritivos de séries temporais e comparações entre os períodos determinados pelos momentos críticos (critical junctures) de mudanças institucionais, tem como pano de fundo a periodização do processo de metropolização concebido por Jurgen Langenbuch em A estruturação da Grande São Paulo (1971). Adotou-se a teoria da causalidade de Paul Pierson, pela qual "os fatos históricos não são elementos definitivos com relações diretas de causa e efeito, mas sim obras complexas da temporalidade" (Lima e Mörschbächer, 2017, p. 112). A complexidade dessa narrativa histórica está na constatação de fatos cujas relações causais evidenciam a política no tempo porque se formam num movimento lento de processos de autorreforço, tendo em vista que seus efeitos se constituem como parte do resultado final a ser considerado num horizonte temporal de longa duração (Pierson, 2004, p. 95).

Para discutir essas questões, o artigo apresenta, além desta introdução e da conclusão, três partes: a primeira trata das diferentes abordagens institucionalistas da governança metropolitana brasileira; em seguida, a discussão sobre os momentos críticos na história institucional do saneamento e da governança metropolitana; por fim, a história institucional do saneamento na RMSP. Os conceitos de path dependency e critical juncture possibilitam compreender processos e marcos regulatórios em quatro períodos da história em questão: o da "Metropolização de Fato" (1946-1967), o do "Planasa" (1967-1986), o do "Vazio Institucional" (1986-2007) e o do "Plansab" (pós-2007). Concluímos com algumas considerações sobre os conflitos federativos na Região Metropolitana de São Paulo, decorrentes das indefinições judiciais sobre a questão da titularidade dos serviços de saneamento em regiões metropolitanas no Brasil. Esse caso, além de demonstrar as consequências deletérias das indefinições decorrentes de arranjos federativos inacabados, demonstra como arranjos cooperativos são frágeis quando não são reforçados pelos diferentes atores e instituições ao longo de sucessivos governos.

\section{Abordagens institucionalistas da governança metropolitana brasileira}

A abordagem institucional, em sentido amplo, volta-se ao estudo das regras, dos procedimentos e da organização formal das instituições, 
bem como do seu impacto na prática político-administrativa. A pesquisa no Brasil, nessa perspectiva institucional ampla, produziu abordagens dos problemas sociopolíticos e institucionais metropolitanos estruturadas em métodos quantitativos e qualitativos e em conceitos teóricos da tradição da ciência política (Souza, 1981; Gouvêa, 2005; Balbim et al., 2012). Numa perspectiva neoinstitucionalista, entre os estudos voltados a produzir conhecimento orientados por pressupostos teórico-conceituais institucionalistas, destacam-se os trabalhos de Garson (2009) e de Machado (2009) que desenvolveram o problema dos dilemas da cooperação das relações intergovernamentais em regiões metropolitanas. 0 primeiro estabelece relação entre fatores históricos, institucionais e políticos para a estruturação fiscal interfederativa. $O$ segundo, a relação entre a redução dos custos transacionais e a implantação de formas de incentivos pelos entes federados, como forma de coordenação dos processos de gestão associada de entes federativos (estudo sobre o consorciamento ou associação voluntária no Grande $A B C$ ) e na associação compulsória de municípios (estudo sobre a Região Metropolitana de Belo Horizonte).

Além dessas abordagens institucionalistas da questão metropolitana, é referência obrigatória o artigo de Souza (2003) a respeito das condicionantes do regime político para a definição constitucional da norma sobre regiões metropolitanas na constituinte de 1988 (inspiração desta pesquisa). Há também o artigo de Fernandes e Wilson (2013, p. 782), para os quais "as causas que levam à problemática das regiões metropolitanas são de curto prazo e o horizonte de tempo na observação de algum resultado mostra-se de longo prazo". Este artigo, diferentemente de Fernandes e
Wilson (2013), busca compreender o problema da governança metropolitana no setor do saneamento por meio de uma análise de longa duração, analisando a formação das RIGs entre os municípios e o Estado dentro do próprio processo de metropolização da Grande São Paulo (ver Pierson, 2004, p. 92). Afinal, tanto o municipalismo, quanto as relações intergovernamentais, necessárias à consecução das políticas públicas supramunicipais, não emergiram na história recente. A federação tripartite está prevista na CF de 1988, mas o exercício da autonomia municipal no âmbito administrativo, financeiro e político está estabelecido desde a promulgação da Constituição de 1934, conforme tratou o assunto Leal (1950, p. 68; Aversa, 2016, p. 102). Tampouco, o problema da efetividade da LNSB, no tocante aos conflitos interfederativos em Regiões Metropolitanas (RMs), não deriva de causas exclusivamente próximas ou mesmo das escolhas de seus legisladores nas últimas décadas, mas, principalmente, das trajetórias institucionais constituídas ao longo do tempo, assim como da forma concreta da expansão urbana na metrópole.

É necessário salientar que, dentro da temática da água, a literatura internacional vem aplicando o conceito de path dependence a outros casos concretos que não dizem respeito às RIGs. Algumas pesquisas demonstram como a tomada de decisão por uma determinada infraestrutura ou por uma determinada política de recursos hídricos e de saneamento constrange a tomada de decisão de atores (Britto, Maiello e QuintsIr, 2018; Welsh Endter-Wada, 2017; Burnham, Endter-Wada e Bardsley, 2016).

As diferentes abordagens institucionalistas em RMs e as diferentes formas de apropriação do conceito de path depedence justificam a necessidade de se aprofundar discussão 
metodológica de aplicação dos principais conceitos do institucionalismo histórico. Em especial, os conceitos de dependência de trajetória e de conjunturas críticas são fundamentais para a compreensão da interação entre os atores e as mudanças institucionais, numa perspectiva da política no tempo (Pierson, 2004).

Um processo de dependência de trajetória é uma narrativa que representa a mudança institucional no tempo, considerando a situação crítica (critical juncture), marco institucional e temporal: diversos atores interagem em sucessivos eventos, diante de múltiplas possibilidades, até que a consolidação de uma trajetória dependente, em virtude da qual se estabelece uma inércia caracterizada pelo equilíbrio na interação dos atores resistente a outras possibilidades superadas (ibid.). Tal forma de compreensão histórica possibilita, aos institucionalistas, analisarem criticamente a relação de causalidade em processos de mudanças institucionais (ibid.; Thelen, 2000). Em outras palavras, a ocorrência de determinado fato dispara a formação de uma trajetória histórica, num ambiente de luta pelo poder, marcado pelo conflito e pelas contingências temporais entre grupos de ganhadores e de perdedores numa permanente tensão (Mahoney e Thelen, 2010). Se o processo inicial é sucedido por decisões que se autorreforçam com o passar do tempo, observa-se a formação da dependência de trajetória. 0 autorreforço também pode ser denominado feedback positivo, como conceito derivado da ideia de retornos crescentes da economia (Pierson, 2004, p. 22; Lima e Mörschbächer, 2017, p. 109).

Pierson (2004) apresenta quatro propriedades de um processo de dependência de trajetória, como um fenômeno político-social, que distingue sua abordagem de outras da escolha racional ou de caráter econômico: múltiplos equilíbrios, contingência, tempo da ocorrência e sequência de eventos (timing and sequencing) e inércia (p. 44). Na situação inicial, múltiplos equilíbrios derivam da condição de existência de um conjunto de possibilidades de resultado. A realização do evento é contingencial, podendo ocorrer ou não e, em ocorrendo, pode ou não ter consequências duradouras. 0 timing and sequencing ou o quando e a sequência dos eventos são cruciais na formação da trajetória dependente ou, ocorrendo muito tarde, podem não ter efeito algum. Uma vez estabelecida a trajetória dependente, o feedback positivo orientará a interação entre atores e instituições a um equilíbrio singular que se apresentará resistente ao retorno à situação anterior, bem como a uma nova mudança (ibid.).

Já, o momento crítico poder ser considerado como parte do processo de consolidação de uma trajetória dependente. As conjunturas críticas são caracterizadas por eventos que influenciam significativamente a ação política, tornando flexíveis as bases estruturais da instituição vigente por um período relativamente curto, momento no qual o poder político é expandido para revisão das regras do jogo, e suas decisões ou omissões se tornam legados para a constituição da nova matriz institucional (Capoccia e Kelemen, 2007, p. 343). A entrada em vigência das normas que definem as regras do jogo pode ser considerada como momento crítico (critical juncture). Entretanto, a existência de uma nova regra do jogo é somente parte de um processo de dependência de trajetória (Pierson, 2004, p. 53). O momento da formalização legal de uma das trajetórias pode não significar a sua imediata efetivação, se, principalmente, se tratar de mudanças complexas 
entre as quais estão aquelas de caráter administrativos e operacionais que regulamentam a definição legal do sistema de incentivos e restrições às ações individuais e coletivas. Por fim, o momento do efetivo fechamento para outras trajetórias (lock-in) representa a finalização do processo de mudança institucional com seu arcabouço de regras constitucionais e operacionais. Conforme afirmou Mahoney, "uma vez selecionada uma particular opção, torna-se progressivamente mais difícil o retorno para o ponto inicial, quando múltiplas alternativas estão ainda disponíveis" (2000, p. 513). Entretanto, a configuração do momento crítico não significa que as outras trajetórias até então disponíveis venham a ser descartadas.

Esta pesquisa, juntamente com grande parte da pesquisa em institucionalismo histórico, dirige-se a identificar padrões de dependência de trajetória. Por isto, a reconstrução dos processos históricos macroestruturais das instituições assume grande importância (Lima e Mörschbächer, 2017, p. 109). São tomadas como momentos críticos (critical junctures), a Constituição Federal de 1946, a Carta Outorgada de 1967-69, a Constituição Federal de 1988 e a lei federal n. 11.445, de 2007 (LNSB). Esses momentos são os pontos de partida e de chegada de possibilidades de relações intergovernamentais (RIGs) dentro dos respectivos marcos institucionais inscritos nos pactos federativos (ou regras do jogo federativo). Nas práticas das interações entre os atores, as racionalidades federativas inscritas nas Constituições importam na extensão dos sentidos normativos estabelecidos nos regimes constitucionais (Streeck e Thelen, 2005). E, mais, os dispositivos federativos das constituições, como objetos empíricos, podem ser considerados como manifestações discursivas e concretas da situação crítica (Broschek, 2011, p. 547; Schmidt, 2010, p. 4). Nas próximas seções, o caso concreto da cooperação intergovernamental para a implantação das primeiras redes e infraestrutura de saneamento na metropolização de São Paulo é analisado no sentido de se delinear o traço histórico dessa política num período de longa duração, que se inicia com a virada da industrialização e urbanização de São Paulo, na década de 1940, percorrendo até a análise da situação em que se encontra a implementação das regras de cooperação federativa previstas na lei federal n. 11.445/2007.

\section{Momentos críticos na história institucional do saneamento e da governança metropolitana da Grande São Paulo}

No início do período denominado, por Langenbuch (1971, p. 178), "Grande Metropolização de São Paulo" (pós-1940), foram firmados pactos jurídicos considerando os municípios de Santo André, São Bernardo do Campo e São Caetano do Sul como uma territorialidade única, para a implantação do abastecimento de água na região. Primeiro, foi a adução provisória do Sistema Rio Claro (1948), infraestrutura criada originalmente para atender a capital. Depois, foi a implantação definitiva do Sistema Rio Grande (1958). Com a necessidade de implantação de infraestruturas regionais, os atores governamentais estabeleceram formas de cooperação intergovernamental que consistiram em pactos jurídicos entre os municípios e os serviços estaduais de saneamento: a Repartição de Água e Esgoto (1893 a 1954) e o Departamento de Água e Esgoto 
(1954 a 1968). Esses órgãos estaduais tinham atribuição original de atender apenas a capital, mas a metropolização induziu a ampliação territorial de prestação dos saaes (ver Quadro 1). Aos órgãos estaduais, coube o fornecimento de água, medida diretamente da adutora, o que também é conhecido como venda de água no atacado, para que cada um dos municípios realizasse a distribuição local de água potável, de forma interdependente com o prestador estadual.

Essa interação intergovernamental deu origem à dependência de trajetória da prestação interdependente do serviço entre municípios e estado, que permanece até os dias atuais. A pesquisa considerou 20 legislações dos municípios e do estado de São Paulo no período de 1928 a 1955 que apresentaram diferentes arranjos institucionais federativos para a realização da política supramunicipal. Além da possibilidade de prestação interdependente, que se firmou como trajetória dependente, outras três foram depreendidas dos textos normativos: prestação isolada pelo serviço estadual; associação intermunicipal para solução de problemas pontuais; e consorciamento intermunicipal para operar o sistema independentemente dos prestadores estaduais (Aversa, 2016, p. 90). O processo de metropolização, quando se iniciou de fato, impulsionou as relações intergovernamentais entre municípios e estado de São Paulo para a realização dos saaes supramunicipais, que, na RMSP, perduram até hoje como fonte de soluções e de conflitos para a governança metropolitana (De Sousa e Costa, 2013; Costa e Ribeiro, 2013; Heller et al., 2011; Balbim et al., 2012). Até 2019, apenas três municípios, Mauá, São Caetano do Sul e Mogi das Cruzes, operaram de forma interdependente com a
Sabesp. Diadema e Santo André delegaram totalmente seus serviços à Sabesp nos últimos anos em meio a disputas judiciais (Sabesp, 2019, pp. 23-24).

As relações intergovernamentais estabelecidas no processo de metropolização, no contexto municipalista e descentralizador da Constituição de 1946, passaram por um processo de ruptura que se iniciou com as formas centralizadoras e tecnocráticas das regras do jogo autoritárias da Carta de 1967-1969 e que se consolida com a criação da Sabesp em 1973. A partir de então, a política de saneamento estadualista consolida-se em âmbito nacional, passando a coexistir com a trajetória dependente da prestação dos saaes pelos municípios e, no caso da Grande São Paulo, com a interdependência de prestação entre serviços municipais e organizações estaduais.

O quadro de cooperação federativa é alterado com a Política de Saneamento, instituída pela lei n. 5.318, de 26 de setembro de 1967 , quando o governo federal passa a coordenar tecnocraticamente a política de saneamento e, concomitantemente, reforça o poder estadual em detrimento do municipal. Coube ao Ministério do Interior a coordenação da elaboração e execução do Plano Nacional de Saneamento (Planasa). Pelo art. 11 da referida lei, fixou-se uma diretriz que norteou o discurso da execução das políticas urbanas no período autoritário: "a execução do Plano Nacional de Saneamento far-se-á de preferência por intermédio de convênios que promovam a vinculação de recursos dos órgãos interessados de âmbito federal, estadual e municipal". Em termos legais e políticos, a esfera municipal não foi absolutamente excluída do regime tecnocrático centralista do Planasa. A ditadura militar conseguiu, de um lado, operar a política 
(nomeação biônica dos chefes do executivo municipais) dos principais municípios e cidades-região, impedindo a emergência de qualquer conflito intergovernamental; de outro lado, ao aumentar a concentração financeira na União, possibilitou seu maior poder de barganha com os entes subnacionais, por meio do sistema de financiamento das políticas de desenvolvimento urbano. Para Souza (2002), a questão é que os entes subnacionais atuaram de forma decisiva para legitimar o regime ao comporem coalizões que o sustentaram em sua forma não democrática e centralizadora, o que não impediu a permanência do federalismo como uma instituição (p. 31).

No momento do apogeu do Planasa, houve intensa transferência dos serviços municipais para as companhias estaduais de saneamento básico (Cesbs). Os municípios estavam sendo criticados por sua política paternalista em relação à tarifação sobre esses serviços, à incapacidade técnica, à desqualificação dos recursos humanos e à ausência de estrutura administrativa. Em favor das Cesbs, estava colocada a então pretendida viabilização econômica do modelo, por meio da autossustentação tarifária, a partir de uma tarifação única em todo o estado, sob a justificativa da economia de escala que viabilizaria o sistema dentro do território estadual. Isto porque os municípios isoladamente seriam incapazes dessa economia de escala (Rezende e Heller, 2008, p. 270; Arretche, 2000, p. 83). No caso do estado de São Paulo, a Sabesp assumiu a primeira cidade, Botucatu, no ano seguinte ao da sua criação (1974). Dez anos depois, contava com 227 cidades e, em 2019, atuava em 369 dos 645 municípios do Estado (Sabesp, 2019).
O Planasa fez surgir a duplicidade de operadores estaduais e municipais na prestação dos saaes, quando, de fato, isso já ocorria na Grande São Paulo com a organizações estaduais operando na capital desde a encampação da Companhia Cantareira de Esgotos (1893) (Sachs, 1982, p. 42). Para De Sousa e Costa (2013, p. 591), "foi o início de uma relação assimétrica e conflitiva entre estados e municípios: a transferência da gestão verticalizada para os primeiros passou pela submissão política dos últimos". Pode-se identificar um encontro conflituoso entre a inquestionável trajetória municipalista dos serviços de saneamento desde a formação das cidades brasileiras que se enfraquece com a trajetória estadualista imposta "de cima-para-baixo" pelo Planasa.

O processo de redemocratização, que culmina com a promulgação da Constituição Federal de 1988, um dos momentos críticos (critical juncture) mais importantes para a governança metropolitana, de um lado, nega o legado autoritário do modelo de gestão tecnocrática e centralizada dos militares e, de outro, lega um vazio de governança metropolitana ou uma abertura à decisão do legislador estadual. De acordo com Souza (2003), a gestão metropolitana legada pelo Regime Militar de 1964 consiste numa equação "centralismo + autoritarismo", e o processo constituinte de 1988 propõe uma agenda da Reforma Urbana de bases pluralista e descentralizadora (pp. 140 e 153).

Do fim do BNH, em 1986, à vigência da lei federal n. 11.445, de 5 de janeiro de 2007 (LNSB), o setor do saneamento passou por um período de transição e de paralisia de investimentos que desorganizou a prestação dos 
serviços, obrigando os saaes a se adequarem somente às receitas auferidas com as próprias tarifas e as escassas receitas municipais, ao longo de boa parte desses 26 anos de vazio institucional do setor de saneamento. Por mais importante que tenham sido algumas iniciativas nesse período, como a criação do Sistema Nacional de Informações do Saneamento, do Programa Nacional de Combate ao Desperdício de Água e do Programa de Modernização do Setor do Saneamento, essas experiências acumularam para formulação do que viria a ser estabelecido na Lei como "Política Federal do Saneamento Básico".

Em síntese, o caso do saneamento na RMSP possibilita conceber uma periodização da história institucional recente da governança metropolitana em quatro períodos: da metropolização de fato, do Planasa, do vazio institucional e da política pública de saneamento básico: ${ }^{3}$

1) O período da metropolização de fato consiste na inexistência de marco institucional de governança metropolitana, em que pese o processo de metropolização e conurbação que rompem com a delimitação territorial municipal, a partir de década de 1940 (Langenbuch, 1971, p. 98; Santos 2009, p. 77). A inexistência das instituições de cooperação metropolitana não significa a inexistência de marcos institucionais de cooperação federativa intermunicipal. Pois, tal possibilidade já estava prevista na Constituição do Estado de São Paulo desde 1891, no sentido de permitir o agrupamento de municípios da mesma região para instalação, administração e exploração de serviços comuns (Aversa, 2016, p. 104).

2) O período do Planasa, de 1967 a 1986, que se inicia com a vigência da Carta Outorgada de 1967, é caracterizado pela centralização tecnocrática das RMs e a política de saneamento do regime militar. 0 ano de 1967 também é definido como momento de conjuntura crítica em razão da edição da lei n. 5.318/1967. E, o ano de 1986, como fim do período, em razão do decreto-lei n. 2.291/1986, que extinguiu o BNH e transferiu suas atribuições à Caixa Econômica Federal. 0 período contou com uma estrutura administrativa e financeira que centralizava processos tecnocráticos de decisão da política urbana na qual se incluía a de saneamento (ibid., p. 113 e ss.; Rezende e Heller, 2008, p. 269 e ss).

3) 0 período do vazio institucional, no âmbito do saneamento, iniciou-se em 1986 e foi finalizado com a entrada em vigência da LNSB em 2007. Este período de indefinição foi marcado por transferências das políticas de habitação e de saneamento para diferentes ministérios e órgãos financiadores, além, é claro, por ter sido caracterizado pela crise financeira. Boa parte da literatura de saneamento criticou esse período denominando-o "vazio institucional", tendo em vista que as disputas pela titularidade dos serviços e as tentativas de abertura do setor à iniciativa privada dificultaram a criação de consenso para tramitação dos projetos de lei no Congresso Nacional (Rezende e Heller, 2008, p. 284; Costa e Ribeiro, 2013, p. 477; Heller et al., 2011, p. 148 e p. 177).

Já, em relação às instituições metropolitanas, a discussão sobre o vazio institucional é muito mais complexa. Nesse aspecto, reside a importância deste artigo ao definir o estudo do caso das relações interfederativas para a gestão supramunicipal do saneamento na RMSP. Pois, as definições da LNSB permitiram a formalização das relações intergovernamentais entre municípios metropolitanos, estado de São Paulo e Sabesp, conforme a situação 
apresentada no Quadro 2 (penúltima seção). Uma delas foi a emenda constitucional n. 19, de 1998, que instituiu a gestão associada, possibilitando formas voluntárias e descentralizadas de composição entre os entes federativos, por meio dos consórcios públicos e convênio de cooperação interfederativos, o que veio a ser regulamentado pela lei federal n. 11.107, de 6 de abril de 2005 (Lei dos Consórcios Públicos). Com base nesse estudo de caso, pode-se afirmar que a LNSB 2007 é um marco de mudança institucional que finaliza o período de vazio institucional, uma vez que os contratos de programa firmados entre municípios, estado de São Paulo e Sabesp se consolidam como um avanço em relação ao "cheque em branco" que as municipalidades concediam à companhia estadual até então. Com o Estatuto da Metrópole, que tramitava desde 2004 e foi promulgado com a lei n. 13.089 , de 12 de janeiro de 2015, ficaram ratificados dispositivos para uma gestão democrática das regiões metropolitanas já estabelecidos na Constituição Federal de 1988. Por se tratar de lei ordinária, em nada altera a previsão de competência dos estados para criar e definir as formas compulsórias político-administrativas regionais ou supramunicipais, assim como não trata de financiamento. 0 problema é que a instituição de consórcios não ocorre sem a coordenação política de um grupo de municípios ou do ente federativo estadual e/ou nacional, o que pressupõe o desafio dos dilemas cooperativos e de custos transacionais (Garson, 2009; Machado, 2009; Abrucio, Franzese e Sano, 2010).

4) O período da política pública do saneamento básico, pós-2007, representa não só um armistício entre municipalistas e estadualistas, o que possibilitou a manutenção da trajetória de convivência dos dois tipos de prestadores, mas também a definição de uma política pública para além das diretrizes tecnocráticas de investimentos do Planasa que incluiu a definição dos marcos legais de contratação de concessionárias privadas de saneamento. No início de 2013, após 13 anos de tramitação das Ações Diretas de Inconstitucionalidade (ADIs) 1842-RJ e 2077-BA, o Supremo Tribunal Federal declarou inconstitucionais os dispositivos normativos de leis estaduais do Rio de Janeiro e da Bahia que isolavam competências de governança metropolitana na esfera estadual. Entretanto, as ADIs ainda pendem de decisão definitiva. Apesar do rico debate registrado nos votos dos ministros, inclusive apontando formas de governança metropolitana, a decisão na ADI 1842-RJ, ainda não definitiva, restringe-se a declarar inconstitucionais determinados dispositivos que centralizaram as decisões metropolitanas em órgãos estaduais.

A partir do período da Política Pública do Saneamento Básico, com a LNSB e a Lei de Consórcios, foram criadas novas regras para a validade dos contratos de concessões do setor de saneamento básico em geral, o que proporcionou ambiente regulado e seguro para a participação privada no setor (Heller, Rezende e Cairncross, 2014, p. 140). A LNSB passou a exigir planos municipais de saneamento básico, estudos de viabilidade econômico-financeiros, normas de regulação e a forma de convênio ou de consórcio para formalizar a gestão associada entre entes federados (art. 11 da LNSB). Ou seja, até a vigência da lei n. 11.445/2007, os municípios assinavam um cheque em branco para as CEBs administrarem os saaes em seu território. Além desses requisitos legais, a LNSB previu as condições particulares relativas ao planejamento, à prestação e à regulação de serviços 
realizados por prestadores interdependentes (art. 12) e de prestação regionalizada de serviços públicos de saneamento básico, em que um único prestador do serviço pode atender a vários municípios contíguos ou não (art. 14). Com maior rigor e precisão técnica, a LNSB estabelece regras para que prestadores regionais, como a Sabesp, que atuem em mais de um município ou que prestem serviços públicos de saneamento básico diferentes em um mesmo município, mantenham um sistema contábil que permita registrar e demonstrar, separadamente, os custos e as receitas de cada serviço, em cada um dos municípios atendidos, possibilitando a apropriação e a distribuição de custos dos serviços por município atendido regionalmente (art. 18).

O Estatuto da Metrópole, por sua vez, reforçou os princípios constitucionais de cooperação federativa, ao buscar apresentar um conteúdo para o que denomina governança federativa, com o "compartilhamento de responsabilidades e ações entre entes da Federação em termos de organização, planejamento e execução de funções públicas de interesse comum" (inciso IV do art. 2ㅇ). O conceito de governança federativa ganhou um capítulo no estatuto, o qual: (1) elenca um conjunto de princípios que a governança interfederativa deve respeitar (art. 60); (2) integra as diretrizes da política urbana para as RMs com aquelas estabelecidas pelo art. 20 do Estatuto das Cidades (art. 7으); e (3) estabelece uma estrutura básica de processo decisório da instituição metropolitana (art. 8ㅇ).

As mudanças institucionais do saneamento estão em relação direta com a história brasileira. Se o legado histórico importa para as mudanças institucionais, não se pode apenas considerar as causas próximas ao novo marco institucional da Constituição de 1988 e da Lei Nacional de Saneamento Básico de 2007, para identificar trajetórias dependentes que estão colocadas no cenário atual de interação conflituosa entre os atores na política de saneamento. Com a elevação do município ao status de ente federado pela Constituição de 1988 e a indefinição acerca da governança metropolitana, as relações intergovernamentais tornam-se ainda mais complexas, o que traz impactos diretos sobre a implementação da política de saneamento básico na Região Metropolitana de São Paulo, conforme se verá a seguir.

\section{História institucional do saneamento na RMSP: trajetórias cooperativas perdidas, conflitos inevitáveis}

Retomar a história institucional do saneamento dentro do processo de explosão urbana e metropolização da Grande São Paulo possibilita compreender o desenvolvimento das instituições prestadoras dos saaes no momento anterior às regras do jogo tecnocráticas e centralizadoras do Regime Militar de 1964. Esse processo pode ser dividido entre antes e depois da metropolização ocorrida em São Paulo a partir da década de 1940 (Langenbuch, 1971, p. 178). Até a Grande Metropolização de São Paulo, os serviços estaduais de saneamento mantiveram atuação apenas na capital e, nas demais regiões do estado, a Secretaria de Agricultura, Comércio e Obras Públicas manteve apoio para que as cidades implantassem seus próprios sistemas, particularmente para as cidades de Santos e Campinas, dentro do contexto do desenvolvimento da cultura do café 
(Aversa, 2016, p. 76). Após a década de 1940, a necessidade de infraestruturas regionais fica evidente, passando a exigir uma perspectiva regional de enfrentamento das demandas por ampliação dos sistemas de saneamento.

Castro (2016) verifica uma regularidade de existência dos períodos privatista, racional-administrativo e neoprivatista na história dos serviços de saneamento dos países centrais e também das principais cidades da América Latina. Assim como ocorreu nos países Europeus e nos EUA, na capital paulista e em algumas cidades brasileiras, a prestação inicial dos saaes pela iniciativa privada foi sucedida pela encampação do poder público, em virtude da incapacidade das companhias privadas para a gestão da água (como mercadoria), uma vez que são necessários altos investimentos para garantir as condições de salubridade no meio urbano (ibid., p. 437). Com a estatização dos serviços, as organizações prestadoras dos saaes são constituídas dentro modelo burocrático da racional-administração. A forma de gestão racional-administrativa caracteriza-se pelo intenso uso da tecnologia e organização burocrática nos moldes weberiano das organizações prestadoras desses serviços, conduzida por pessoal técnico e administrativamente capacitado, e pelo processo crescente de regulação das atividades privadas, seja por meio da gestão centralizada na administração pública de organizações de saneamento de atuação em grande escala, seja pelo aumento de controle e de intervenção direta do Estado em praticamente todas as esferas da sociedade (ibid., p. 439). Esse período foi sucedido pelo neoprivatista, caracterizado pela disputa de grandes empresas por espaço junto às organizações públicas para assunção de todo ou parte dos sistemas, impactando a gestão no equilíbrio econômico-financeiro de longo prazo e, consequentemente, as tarifas praticadas. A presença do setor privado nas etapas de produção dos saaes implica o retorno desses serviços ao status de mercadoria e de bens privados adquiridos no mercado, em que a função de mediação do Estado é reduzida e, nos casos extremos, há a transferência da propriedade dos sistemas à iniciativa privada (ibid., p. 443).

O Quadro 1 sintetiza a sucessão de organizações estaduais prestadoras de saaes na Grande São Paulo, combinando os conceitos das periodizações de Castro (2016) e de Langenbuch (1971). Os períodos da pré-metropolização e do início da metropolização são tomados como um único momento, considerando-se a perspectiva das relações intergovernamentais entre estado de São Paulo e municípios da Grande São Paulo, em detrimento da perspectiva da história do urbanismo.

As administrações da CIA Cantareira e Esgotos e da RAE foram concebidas somente para a implantação e operação dos sistemas de saneamento da capital paulista sob a responsabilidade de órgãos estaduais (Aversa, 2016, p. 73). Em que pese a atribuição formal da RAE estar adstrita à capital, a repartição estadual formalizou contrato de fornecimento de água no atacado para as cidades de Santo André, São Bernardo do Campo e São Caetano do Sul (ABC) em 1949. O DAE, autarquia estadual, é criado em 1954 com a atribuição de atuar em determinados municípios da Grande São Paulo (GSP), para operar os sistemas integrados, além de continuar a trajetória de organização estadual prestadora dos saaes da capital paulista. Com a grande metropolização, é que as organizações estaduais passam a ter a atribuição para a atuação junto às demais cidades da GSP, sucessivamente: DAE (1954-1968), 
Quadro 1 - Periodização e cronologia das organizações do estado de São Paulo de prestação dos saaes

\begin{tabular}{|c|c|c|c|}
\hline $\begin{array}{l}\text { Processo de } \\
\text { metropolização }\end{array}$ & Períodos do saneamento & Organizações estaduais & Território de atuação \\
\hline \multirow{2}{*}{$\begin{array}{l}\text { Pré-metropolização } \\
\text { (1875 - 1915) } \\
\text { Início da Metropolização } \\
\text { (1915 - 1940) }\end{array}$} & Privatista & $\begin{array}{l}\text { Cia Cantareira } \\
(1875-1892\end{array}$ & \multirow{2}{*}{ Cidade de São Paulo } \\
\hline & Racional administrativo & $\begin{array}{l}\text { RAE } \\
(1893-1954)\end{array}$ & \\
\hline \multirow{5}{*}{$\begin{array}{l}\text { Grande metropolização } \\
\text { (pós-1940) }\end{array}$} & Racional administrativo & $\begin{array}{l}\text { DAE } \\
(1954-1968)\end{array}$ & Grande São Paulo \\
\hline & Racional administrativo & $\begin{array}{l}\text { Saec (capital) } \\
\text { (1968 - 1973) }\end{array}$ & Cidade de São Paulo \\
\hline & Racional administrativo & $\begin{array}{l}\text { Comasp } \\
(1968-1973) \\
\text { Sanesp } \\
(1970-1973)\end{array}$ & RMSP \\
\hline & Racional administrativo & $\begin{array}{l}\text { Sabesp pública } \\
\text { (capitais públicos) } \\
\text { (1973 - 1997) }\end{array}$ & Estado de São Paulo \\
\hline & Neoprivatista & $\begin{array}{l}\text { Sabesp pública e privada } \\
\text { (capital aberto) } \\
\text { (pós-1997) }\end{array}$ & Nacional e internacional \\
\hline
\end{tabular}

Fonte: reformulado de Aversa (2016, p. 62).

Comasp e Sanesp (apenas no âmbito regional, 1968-1973) e Sabesp (desde 1973). Por isso, constata-se que o próprio processo da grande metropolização, além de ser demarcado pela infraestrutura de saneamento supramunicipal, também implica o estabelecimento de relações intergovernamentais capazes de viabilizar a política pública supramunicipal.

Até a centralização nacional da política de saneamento com a instituição do Planasa, a reconstituição histórica das organizações prestadoras dos saaes da Grande São Paulo demonstra uma trajetória equilibrada de construção de cooperação intergovernamental entre os próprios municípios e entre estes e as organizações estaduais de São Paulo. Sob o marco institucional municipalista que estabeleceu as regras do jogo da Constituição de 1946 até o Planasa, as formas de relações intergovernamentais buscaram compor mecanismos de cooperação para o exercício da autonomia municipal na esfera local, assim como formas de cooperação com o Estado para sua atuação regional.

O ponto de partida de uma atuação metropolitana no saneamento está na execução da integração do Sistema Rio Claro com as redes de abastecimento do município de Santo 
André (futuro ABC: Santo André, São Bernardo do Campo e São Caetano do Sul). É com a criação do DAE, autarquia estadual de água e esgoto, que a atribuição formal da atuação metropolitana sai da situação de informalidade organizacional e de abertura às possibilidades de diferentes formas de relações intergovernamentais, para uma definição legal que reforça a experiência de interação horizontal entre o município de Santo André ( $A B C$ ) e a RAE. A realidade crítica de demanda por água potável do município na década de 1940 mobiliza-o a assumir suas responsabilidades de implantação, de financiamento e de operação como ente político-administrativo, viabilizando a implantação da rede de adução do Sistema Rio Claro, uma vez que a RAE concordou com a venda de água no atacado do Sistema que fora planejado para servir exclusivamente à capital. ${ }^{4}$ Os problemas de abastecimento do $A B C$ da década de 1940 são resolvidos com a adução do sistema do Rio Claro de forma precária e, depois, com as instalações do Sistema do Rio Grande, em 1958, e, por fim, voltando a ser também abastecido pelo Sistema Rio Claro com a sua duplicação em 1975. Atualmente o ABC está servido por esses dois sistemas.

Para viabilizar o "Novo Sistema de Abastecimento de Água do ABC", em 1958, a relação intergovernamental definida pressupôs uma única territorialidade do $A B C$. Entretanto, do ponto de vista jurídico, os municípios foram considerados como diferentes pessoas jurídicas, com as quais o governo do Estado e o DAE firmaram o Termo de Acordo e o Convênio em 1955, tendo cada municipalidade os seus próprios direitos e deveres (Aversa, 2016, p. 106).

A partir de década 1960, os serviços passam por nova onda de mudanças para alcançar os recursos de financiamento onerosos federais e internacionais, na forma de sociedade de economia mista. A reorganização do setor segue a divisão operacional já estabelecida no DAE, com sua repartição em Saec, autarquia para prestação na capital, Comasp, companhia para fornecimento de água regional, e Sanesp, companhia para esgotamento sanitário regional. A Saec e os saaes municipais são integrados na forma de prestação interdependente do serviço. À época, o esquema de trajetória dependente foi concebido a partir da figura elaborada pela Coordenação de Projetos Especiais da Saec de Luiz Pontes.

Na Comasp (de atuação em âmbito regional), os municípios passam a ter participação acionária nas companhias metropolitanas. De acordo com Eros Grau, o conjunto de subscrições foi considerado juridicamente como capital autorizado, o que possibilitou a tomada de empréstimo de grande vulto junto ao Banco Interamericano de Desenvolvimento para a implantação do Sistema Cantareira e de outros sistemas regionais (Aversa, 2016, p. 123; Grau, 1968, p. 304). Este foi o ápice da experiência equilibrada e cooperativa de relação interfederativa entre os municípios metropolitanos e o estado de São Paulo, sob a coordenação do Conselho de Desenvolvimento da Grande São Paulo - Codegran (Grau, 1974).

A criação da Sabesp, por um lado, representou a ruptura da trajetória de cooperação entre municípios e estado na Grande São Paulo, à medida que privilegiou as Cesbs em detrimento dos serviços municipais (Rezende e Heller, 2008, p. 270). Por outro lado, não rompeu com a trajetória de prestação interdependente dos serviços, o que poderia ter ocorrido por meio de centralização drástica na Sabesp, eliminando a atribuição municipal para o saneamento em RM. Isto demonstra 
Figura - Esquema de trajetória dependente da prestação interdependente entre prestadores municipais e prestadores estaduais de saneamento da Grande São Paulo
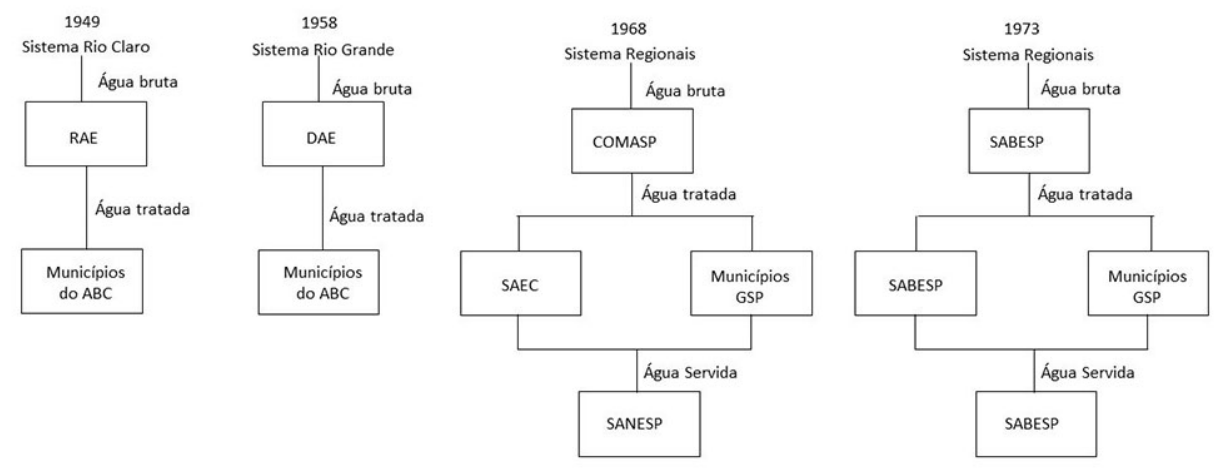

Fonte: elaboração própria (apud Pontes, 1973, p. 12).

que o caso do saneamento comprova a tese de que, mesmo sob o regime do ato institucional n. 5/1968, o federalismo manteve-se como instituição no período autoritário (Souza, 2002, p. 31).

A emergência da trajetória de prestação interdependente, no contexto das regras do jogo democrático da Constituição de 1946, permanece mesmo com a centralização do Planasa no contexto do autoritarismo da Carta de 1967-1969. No primeiro, o contexto democrático em que se realiza o pacto federativo possibilita a interação autônoma dos entes, sob a coordenação do estado de São Paulo, para o enfrentamento das demandas por políticas de desenvolvimento urbano advindas da expansão econômica do café e do início da industrialização. No segundo, a tecnoburocracia centralista, que conduziu o nacional-desenvolvimentismo com prioridade para o Sul e Sudeste, é tanto responsável pelo milagre brasileiro (1968-1972), quanto pelo crescimento da favelização e ocupação desordenada das metrópoles brasileiras (Klink, 2013, pp. 91-93). Nas relações intergovernamentais metropolitanas, antes da constituição da Sabesp, os municípios assumiram papel preponderante na definição, no financiamento e na gestão da política supramunicipal. Com o Planasa e a decorrente centralização burocrática realizada pela Sabesp, municípios e estado distanciaram-se na Grande São Paulo, em virtude da ausência de coordenação metropolitana, mantendo-se vinculados apenas por um elo: a prestação interdependente dos saaes como path dependency. 
Entretanto, o centralismo burocrático do regime de 1964 não representou a origem de todos os conflitos entre municípios e estados na política de saneamento. Deve-se também considerar a onda neoliberal a partir da década de 1990, que conflagra a tensão histórica entre municipalistas e estadualistas no setor de saneamento em diversos campos de disputa: pelo marco regulatório do saneamento; por recursos de financiamento para os investimentos; pelo modelo de gestão público versus privatizado; pela gestão em regiões metropolitanas; e, no caso da RMSP, pela monopolização dos saaes. Já no contexto do neoliberalismo, em que se coloca a possibilidade de participação privada nos serviços municipais e na Sabesp, o conflito assume a forma de concorrência comercial.

A relação horizontal construída entre os municípios do $A B C$ e o estado de São Paulo entre as décadas de 1940 e 1950, para a prestação interdependente dos saaes, demonstra a maturidade institucional tanto para uma definição da autonomia municipal em região metropolitana, quanto para a cooperação federativa necessária ao enfrentamento da demanda explosiva por abastecimento de água do processo de metropolização da Grande São Paulo. Por isto, essa experiência de cooperação federativa se revela como uma herança perdida em face dos conflitos gerados pela reconstituição da trajetória estadualista na forma centralista-burocrática do Planasa e pelo contexto neoprivatista em que os saaes são objeto de concorrência comercial. A partir do Planasa, as regras do jogo possibilitam uma relação assimétrica entre a Sabesp e os municípios, sejam eles metropolitanos ou não, tenham prestação interdependente ou não.
Com o passar dos anos, a Sabesp vem assumindo os serviços municipais de saneamento da RMSP, restando atualmente apenas três da RMSP, São Caetano do Sul, Mauá e Mogi das Cruzes, com prestação interdependente dos saaes. No contexto em que o serviço público essencial dos saaes é tido como um negócio pela companhia estadual, não há espaço para cooperação federativa com autonomia municipal, mas sim para concorrência comercial. Diferentemente do privatismo do século XIX, não se trata apenas de identificar se o prestador dos saaes é uma empresa pública ou privada, mas sim trata-se de compreender os diversos arranjos de direito de propriedade sobre a água: mercantilização, comoditização, constituição de ativos, privatização ou concessão e societarização (Aversa, Empinotti e Klink, 2018 , p. 40). A Sabesp poderia assumir diferentes formas de relações intergovernamentais inclusive para solucionar pendências, como a criação de empresas em que a ela teria participação acionária para a quitação de dívidas e pendências judiciais. É o caso de Diadema que aprovou tal legislação, mas que foi revogada no mandato seguinte, para viabilizar o padrão de gestão metropolitana compartilhada da companhia estadual, que consiste na delegação municipal dos saaes por meio de contrato de programa (Diadema, 2011). Como se verá a seguir, sobre a situação em que se encontra a efetividade da LNSB em relação às RIGs com os municípios da RMSP, a questão é que a Sabesp prefere aguardar a eleição de prefeitos amigos de seu interesse comercial. No contexto do neoprivatismo, discutido acima (Castro, 2016), em que os saaes são operados por empresas de saneamento com capital aberto em bolsas de valores, como a Sabesp e a Thames Water 
Utilities, houve uma mudança institucional de uma governança compartilhada (shared governance) para uma governança de acordo com os interesses dos acionistas (shareholder water governance) (Klink, Empinotti e Aversa, 2019, p. 3; Allen e Pryke, 2013, p. 431).

\section{Mudanças na LNSB: rupturas quando ainda os contratos de programa não foram totalmente implementados na RMSP}

A Lei Nacional de Saneamento Básico (LNSB) estabelece que os contratos de saneamento básico devem estar de acordo com: o plano municipal de saneamento básico atualizado; o estudo de viabilidade técnica e econômico-financeira, comprovando a possibilidade de prestação integral e universal dos serviços; a existência de regulação e fiscalização dos serviços; a realização de audiência prévia e consulta pública sobre o contrato de concessão ou de programa e com outros dispositivos que afastaram a tradição de concessão às companhias estaduais por meio de um "cheque em branco". Essa situação foi um legado do Planasa que perdurou até a entrada em vigência da LNSB em 2007, apesar de a lei federal n. 8.987, de 13 de fevereiro de 1995, a Lei de Concessões, definir os requisitos para a delegação de serviços públicos em geral. Com a redação da LNSB de 2007,5 ficou definido o contrato de programa para as delegações dos serviços às companhias estaduais e os contratos de concessão para as delegações à iniciativa privada. Em outras palavras, a formalização de contratos de programa define a forma pela qual devem ser as relações intergovernamentais entre a Sabesp e os municípios dentro do marco da LNSB.
Para análise da efetividade dessas normas, o Quadro 2 foi concebido, considerando-se três fatores: a legalidade do pacto com o município em relação à LNSB, de 2007; a condição de prestador no atacado ou no varejo; e a abrangência da infraestrutura integrada ou isolada no território metropolitano. Primeiro, há que se considerar se as relações com os municípios estão de acordo ou não com a LNSB. Segundo, deve-se observar se a Sabesp é prestador dos saaes no atacado, mediante uma prestação de serviço interdependente em que os municípios atendem o âmbito local (Mogi das Cruzes, Mauá e São Caetano do Sul); ou, se a Sabesp é prestador direto para os usuários, mediante delegação dos saaes pelos municípios. Em ambos os casos, faz-se necessário avaliar se a RIG está de acordo ou não com a LNSB. Terceiro, deve-se considerar se há integração da infraestrutura dos sistemas de abastecimento de água e de esgotamento sanitário no âmbito territorial supramunicipal ou se o sistema que atende o município é isolado. Com o Quadro 2, pretende-se apresentar todas essas possibilidades:

A Sabesp opera em 369 dos 645 municípios do Estado (Sabesp, 2019, p. 22). No âmbito estadual, o estado de São Paulo, a Sabesp e a Arsesp formalizaram contratos de programa e convênios com 307 municípios, o que equivale a $81,1 \%$ da receita operacional bruta, é só a cidade de São Paulo (contratada em 2010) é responsável por $47 \%$, de acordo com a contabilidade de 2018 (ibid., p. 21). Na RMSP, 10 municípios dos 39 não possuem contratos de programa (ibid.).

No neoprivatismo, os atores não se movem pela simples ideia da universalização do acesso aos saaes. A operação e os investimentos na infraestrutura de saneamento básico 
Quadro 2 - As RIGs na RMSP em relação à Lei Nacional de Saneamento Básico de 2007, segundo a integração ao sistema de abastecimento metropolitano

\begin{tabular}{|c|c|c|c|c|}
\hline \multirow{2}{*}{ Prestador } & \multicolumn{2}{|c|}{ De acordo formal com a LNSB (29 municípios) } & \multicolumn{2}{|c|}{ Em desacordo formal LNSB (10 municípios) } \\
\hline & Integrado & Isolado & Integrado & Isolado \\
\hline Municipal & Mogi das Cruzes (leste) & & $\begin{array}{l}\text { Mauá, } \\
\text { São Caetano do } \\
\text { Sul }\end{array}$ & \\
\hline Sabesp & $\begin{array}{l}\text { Francisco Morato, Franco da } \\
\text { Rocha, Caieiras, São Paulo, } \\
\text { Arujá, Suzano, Ferraz de } \\
\text { Vasconcelos, Rio Grande da } \\
\text { Serra, Ribeirão Pires, Diadema, } \\
\text { Barueri, Itapevi, Cotia, Embu, } \\
\text { Taboão da Serra, Itapecerica } \\
\text { da Serra, Embu-Guaçu, Santo } \\
\text { André, Guarulhos, São Bernardo } \\
\text { do Campo, Itaquaquecetuba, } \\
\text { Poá, Carapicuíba }\end{array}$ & $\begin{array}{l}\text { Mairiporã, } \\
\text { Santa Isabel, } \\
\text { Cajamar, } \\
\text { Guararema, } \\
\text { Salesópolis }\end{array}$ & $\begin{array}{l}\text { Jandira, } \\
\text { Osasco, } \\
\text { Vargem Grande } \\
\text { Paulista }\end{array}$ & $\begin{array}{l}\text { Biritiba-Mirim, } \\
\text { Santana de Parnaíba, } \\
\text { Pirapora do Bom Jesus, } \\
\text { São Lourenço da Serra, } \\
\text { Juquitiba }\end{array}$ \\
\hline
\end{tabular}

Fonte: elaboração própria (atualização 11/2019 de Aversa, 2016, p. 134, apud Arsesp, s/d). Obs.: considerando a redação original da LNSB de 2007 a respeito do contrato de programa.

envolvem uma complexa economia política, na qual atores municipais, estaduais e empresas privadas equacionam interesses por longos períodos, geralmente de 30 anos ou mais, conforme as responsabilidades contratuais. Assim, as relações intergovernamentais nos setores de infraestrutura tendem a possuir custos transacionais elevados, se se considerarem os interesses políticos e econômicos dos atores envolvidos.

A participação privada pode ocorrer, por meio de contratos de concessão e de parcerias público-privadas e também por meio da participação acionária nas empresas de saneamento (Britto e Rezende, 2017; Klink e Souza, 2017). A regulamentação da Lei de Concessão (lei n. 8.987/1995), no governo Fernando Henrique Cardoso, e da Lei das
Parcerias Público-Privadas (lei n. 11.079/2004), no governo Lula, criaram as condições de segurança jurídica para a inserção da iniciativa privada na execução dos serviços e obras de infraestrutura, reforçando a trajetória privatista que, até então, fora abandonada em favor da burocracia racional-administrativa estatal. Recentemente, a lei n. 14.026, de 15 de julho de 2020, alterou substancialmente a LNSB vigente desde 2007, promovendo uma ruptura com o municipalismo do tipo de baixo-para-cima da LNSB original. Essa lei foi aprovada, após duas tentativas de aprovação de textos similares nas medidas provisórias n. 844/2018 e 868/2018, que perderam a eficácia por decurso de prazo sem votação. A Lei visa ampliar as condições de segurança jurídica para a participação privada com alteração de dispositivos sobre normas 
uniformizadas de regulação dos serviços para a Agência Nacional das Águas, sobre a titularidade dos saaes, sobre estruturas de governança interfederativa, sobre a competição entre iniciativa privada e companhias estaduais de saneamento e sobre alienação de controle acionário de empresas públicas e sociedade de economia mista (relator Zuliani, 2019). Particularmente em relação às RIGs, destacam-se duas alterações: definição de âmbitos territoriais de prestação regional a serem instituídos pelos Estados e União (art. 3ํ, Vl; art. 52, § 3ㅇ); a vedação de contrato de programa sem prévia licitação (art. 8oㅡㄴ) e a vedação do contrato de programa como forma precária de pactuação entre municípios e estados (art. 10). A validade dessa Lei é questionada pela Ações Direta de Inconstitucionalidade (ADI) n. 6492, ajuizada pelo Partido Democrático Trabalhista, e a ADI n. 6536, pelo Partido Comunista do Brasil e Partido Socialismo e Liberdade (STF, 2020).

\section{Conclusão}

Este artigo buscou compreender a implementação da LNSB na RMSP, como resultado de um processo de mudança institucional num amplo horizonte temporal, em que se deram as relações entre municípios e estado para a realização da política de saneamento supramunicipal. A necessidade de infraestruturas regionais de saneamento é decorrente da metropolização, o que trouxe desafios e, até hoje, continua trazendo para os atores governamentais.

0 estudo sobre a forma pela qual se constituiu a trajetória da interdependência na prestação dos saaes na RMSP possibilitou demonstrar que as relações de cooperação para o saneamento metropolitano ocorreram num ambiente de cooperação e respeito à autonomia municipal conquistada nas Constituições Federais de 1934 e de 1946. Essa trajetória é parcialmente rompida com a formação da trajetória de prestação dos saaes estadualista do Planasa no contexto da tecnocracia autoritária do regime de 1964 . No que diz respeito à cooperação metropolitana, há um rompimento das relações entre municípios e estado, mas, em relação aos saaes, a trajetória está mantida até os dias de hoje na relação entre a Sabesp e os serviços municipais das cidades de Mauá, de São Caetano do Sul e de Mogi das Cruzes. Dessas relações intergovernamentais, apenas a com Mogi das Cruzes pode ser considerada formalmente válida de acordo com as regras de formalização da RIG, por meio do contrato de programa, conforme redação da LNSB de 2007.

Este trabalho aponta três inovações para a literatura sobre o tema. Primeiro, atualiza-se o velho debate sobre a disputa da titularidade do saneamento em regiões metropolitanas, por meio da análise histórico-institucional das relações intergovernamentais concretamente estabelecidas na Grande São Paulo no processo de metropolização da política de saneamento, valendo-se dos pressupostos metodológicos do institucionalismo histórico de Pierson (2004). Segundo, identificaram-se os marcos históricos do saneamento na metropolização da Grande São Paulo que se deu com a adução do Sistema Rio Claro (1949) e a implantação do Sistema Rio Grande (1958) para o abastecimento das cidades de Santo André, São Bernardo do Campo e São Caetano do Sul. A implantação da rede técnica que integra o território para além dos limites municipais é um fato demonstrativo e significativo do processo de metropolização 
do saneamento na Grande São Paulo, que comprova as teses sobre a urbanização paulistana e brasileira (Langenbuch, 1971; Santos, 2009). Terceiro, apesar de esta pesquisa não ousar discutir as questões sobre os dilemas para a cooperação em RMs ou por que as RMs continuam ingovernáveis, o debate político, histórico e institucional sobre as RIGs em regiões metropolitanas revela a necessidade de aprofundar as pesquisas sobre os processos políticos e econômicos que incentivam ou restringem a cooperação dos atores que, no atual contexto, passa pela sociedade, pelo Estado e pelo mercado (Swyngedouw, 2013).

\section{[I] https://orcid.org/0000-0002-4921-9930}

Universidade Federal do ABC, Programa de Pós-Graduação em Planejamento e Gestão do Território. São Bernardo do Campo, SP/Brasil.

m.aversa@uol.com.br

\section{[II] http://orcid.org/0000-0001-8916-4981}

Universidade Federal do ABC, Programas de Pós-Graduação em Planejamento e Gestão do Território e Pós-Graduação em Políticas Públicas. São Bernardo do Campo, SP/Brasil.

vanessa.oliveira@ufabc.edu.br

\section{Nota de agradecimento}

Agradecemos aos revisores pelos apontamentos que possibilitaram o aprimoramento do artigo e, particularmente, pela participação no processo de amadurecimento desta pesquisa, aos componentes das bancas de qualificação e de defesa: Conrado Hubner, Klaus Frey e Leo Heller. 


\section{Notas}

(*) Este trabalho é resultado da dissertação de mestrado no Programa de Pós-Graduação em Planejamento e Gestão do Território da UFABC que, em continuidade no doutoramento no mesmo Programa, compõe o grupo de pesquisa Governança Democrática de Saneamento Ambiental integrante do Projeto Temático "Governança Ambiental da Macrometrópole Paulista face a vulnerabilidade climática (2017-2022)", financiado pela Fundação de Amparo à Pesquisa do Estado de São Paulo - Fapesp (Processo n. 15/03804-9).

(1) O conceito legal de saneamento básico compreende o abastecimento de água, o esgotamento sanitário, a limpeza urbana e resíduos sólidos e a drenagem de águas pluviais urbanas. Este artigo utiliza o termo "saneamento" ou Saaes para fazer referência aos dois primeiros componentes.

(2) LNSB: "art. 12. Nos serviços públicos de saneamento básico em que mais de um prestador execute atividade interdependente com outra, a relação entre elas deverá ser regulada por contrato e haverá entidade única encarregada das funções de regulação e de fiscalização". Essa redação não foi alterada pela lei n. 14.026, de 15 de julho de 2020.

(3) Para elaboração desta periodização, foram consideradas outras, concebidas por Ana Lúcia Britto, no trabalho coordenado por Heller et al. (2011, p. 34) e por Rezende e Heller (2008, p. 277).

(4) O Sistema Rio Claro foi inaugurado em 1939, após muita controvérsia em relação a captação de mananciais distantes em detrimento da proteção e da prática de abastecimento do rio Tietê (Oliveira, 1958).

(5) O contrato de programa passou a ser vedado pela lei federal n. 14.026/2020, que alterou substancialmente a LNSB. Pelo art. 8 o, II, e pelo art. 10, o contrato de programa ficou vedado. A Tabela 2 está de acordo com a redação original da LNSB de 2007.

\section{Referências}

ABRUCIO, F.; FRANZESE, C.; SANO, H. (2010). "Coordenação e cooperação no federalismo brasileiro: avanços e desafios". In: CUNHA, A. S.; MEDEIROS, B. A.; AQUINO, L. C. (orgs.). Estado, instituições e democracia: República. Brasília, Ipea, pp. 177-212.

ARRETCHE, M. T. S. (2000). Estado federativo e políticas sociais: determinantes da descentralização. Rio de Janeiro, Revan.

(2007). A Agenda institucional. Revista Brasileira de Ciências Sociais. São Paulo, v. 22, n. 64, pp. 147-151.

ALLEN, J.; PRYKE, M. (2013). Department Financialising household water: Thames Water, MEIF, and 'ringfenced' politics. Cambridge Journal of Regions, Economy and Society. Cambridge, v. 6, pp. 419-439.

ARSESP - Agência Reguladora de Saneamento e Energia do Estado de São Paulo (s/d). Municípios conveniados. Disponível em http://bit.do/ficf7. Acesso em: 18 nov 2019.

AVERSA, M. (2016). História institucional do saneamento e da metropolização da Grande São Paulo: trajetórias perdidas, conflitos inevitáveis. Dissertação de mestrado. Santo André, Universidade Federal do ABC. 
AVERSA, M.; EMPINOTTI, V. L.; KLINK, J. (2018). Água: mercadoria, bem comum ou direito? Algumas contradições na implementação da política pública de direitos humanos de acesso à água e ao saneamento. Waterlat-Gobacit N. W. Papers, v. 5, pp. 31-52.

BALBIM, R. N. et al. (2012). Desafios contemporâneos na gestão das regiões metropolitanas. Revista Paranaense de Desenvolvimento. Curitiba, n. 120, pp. 149-176.

BRITTO, A. L; REZENDE, S. (2017). A política pública para os serviços urbanos de abastecimento de água e esgotamento sanitário no Brasil: financeirização, mercantilização e perspectivas de resistência. Cadernos Metrópole. São Paulo, v. 19, n. 39, pp. 1517-2422.

BRITTO, A. L.; MAIELLO, A.; QUINTSLR, S. (2019). Water supply system in the Rio de Janeiro Metropolitan Region: open issues, contradictions, and challenges for water access in an emerging megacity. Journal of Hydrology. Amsterdam, v. 573, pp. 1007-1020. Disponível em: doi: http://bit.do/fiCpR. Acesso em: 25 nov 2019.

BROSCHEK, J. (2011). Conceptualizing and theorizing constitutional change in federal systems: insights from historical institutionalism. Regional and Federal Studies. Londres, v. 21, n. 4/5, pp. 539-559.

BUJAK, N. L. (2018). Políticas públicas de saneamento básico: fatores institucionais nas regiões metropolitanas de São Paulo e Buenos Aires entre 1990 e 2015. Tese de doutorado. São Paulo, Universidade de São Paulo.

BURNHAM, M.; MA, Z.; ENDTER-WADA, J.; BARDSLEY, T. (2016). Water management decision making in the face of multiple forms of uncertainty and risk. JAWRA Journal of the American Water Resources Association, ed. 52, n. 6, pp. 1366-1384.

CAPOCCIA, G.; KELEMEN, R. D. (2007). The study of critical junctures: theory, narrative, and counterfactuals in historical institutionalism. World Politics. Baltimore, The Johns Hopkins University Press, v. 59, n. 3, pp. 341-369.

CASTRO, J. E. (2016). Água e democracia na América Latina. Campina Grande, EDUEPB.

COLLIER, R. B.; COLLIER, D. (1991). Shaping the political arena: critical junctures, the labor movement and regime dynamics in Latin America. Princeton, University Press.

COSTA, S. S. da; RIBEIRO, W. A. (2013). "Dos porões à luz do dia: um itinerário dos aspectos jurídicos-institucionais do saneamento básico”. In: HELLER, L.; CASTRO, J. E. Política pública e gestão de serviços de saneamento. Belo Horizonte, Ed. UFMG, pp. 467-482.

DE SOUSA, A. C. A. de; COSTA, N. R. (2013). Incerteza e dissenso: os limites institucionais da política de saneamento brasileira. Revista de Administração Pública. Rio de Janeiro, v. 47, n. 3, pp. 587-600.

(2016). Política de saneamento básico no Brasil: discussão de uma trajetória. História, Ciências, Saúde - Manguinhos. Rio de Janeiro, v. 23, n. 3, pp. 615-634.

DIADEMA (2011). Lei municipal n. 3.123, de 29 de julho de 2011, que dispõe sobre a criação da Companhia de Água e Esgoto de Diadema - Caed. Disponível em: http://bit.do/fiCec. Acesso em: 19 nov 2019.

FERNANDES, A. S. A.; WILSON, R. H. (2013). Mudança institucional e gestão metropolitana no Brasil: o municipalismo autárquico e as finanças municipais metropolitanas. Revista Administração Pública. Rio de Janeiro, v. 47, n. 3, pp. 777-800.

GARSON, S. (2009). Regiões metropolitanas: por que não cooperam? Rio de Janeiro, Letra Capital; Belo Horizonte, PUC. 
GOMIDE, A. Á. (2011). A Política das Reformas Institucionais no Brasil: a reestruturação do setor de transportes. Tese de doutorado. São Paulo, Escola de Administração de Empresas de São Paulo.

GOUVÊA, R. G. (2005). A questão metropolitana no Brasil. Rio de Janeiro, Editora FGV.

GRAU, E. R. (1968). COMASP - Sociedade anônima de capital autorizado. Revista DAE. São Paulo, ed. 72, n. 784, pp. 301-304.

(1974). Regiões Metropolitanas - Regime jurídico. São Paulo, Bushatsky.

HELLER, L. et al. (coord.). (2011). Panorama do saneamento básico no Brasil. Brasília, Ministério das Cidades (versão de 17/6/2011).

HELLER, L.; REZENDE, S. C; CAIRNCROSS, S. (2014). Water and sanitation in Brazil: the public-private pendulum. Municipal Engineer. Londres, Institution of Civil Engineers Publishing, v. 167, pp. 137-145.

KLINK, J. (2013). “Por que as regiões metropolitanas continuam tão ingovernáveis?". In: FURTADO, B. A. et al. Território metropolitano, políticas municipais: por soluções conjuntas de problemas urbanos no âmbito metropolitano. Brasília, Ipea, pp. 83-113.

KLINK, J.; SOUZA, M. B. (2017). Financeirização: conceitos, experiências e a relevância para o campo do planejamento urbano brasileiro. Cadernos Metrópole. São Paulo, v. 19, n. 39, pp. 379-406.

KLINK, J. J.; EMPINOTTI, V. L.; AVERSA, M. (2019). On contested water governance and the making of urban financialisation: exploring the case of metropolitan São Paulo, Brazil. Urban Studies, pp. 1-20. DOI: $10.1177 / 0042098019844390$.

LANGENBUCH, J. R. (1971). A estruturação da Grande São Paulo - Estudo de Geografia Urbana. Rio de Janeiro, Fundação IBGE.

LEAL, V. N. (1950). Leis Municipais. Revista Brasileira dos Municípios. Rio de Janeiro, ABM e IBGE, v. 3, n. IX, pp. 67-73.

LEÃO, L. S. (2013). Bringing historical sociology and path-dependence together: A case study of the Brazilian political economy (1930-2000). Historical Social Research, v. 38, n. 2, pp. 172-196.

LIMA, E. L. N. B. O.; MÖRSCHBÄCHER, M. (2017). Contribuições e desafios do institucionalismo histórico na Ciência Política contemporânea. BIB. São Paulo, n. 81, pp. 103-122.

MACHADO, G. G. (2009). Gestão Metropolitana e Autonomia Municipal. Dilemas das transações federativas. Belo Horizonte, Editora PUC-Minas.

MAHONEY, J. (2000). Path dependence in historical sociology. Theory and Society, v. 29, n. 4, pp. 507-548.

MAHONEY, J.; THELEN, K. (2010). “A theory of gradual institutional change”. In: MAHONEY, J.; THELEN, K. (eds.). Explaining institutional change: ambiguity, agency and power. Cambridge, Cambridge University Press, pp. 1-37.

MENICUCCI, T. M. G. (2009). Ruptura e continuidade: a dinâmica entre processo decisório, arranjos institucionais e contexto político - o caso da política de saúde. Juiz de Fora, UFJF, n. 15, pp. 47-69.

OLIVEIRA, W. E. de (1958). Novo sistema de abastecimento de água para os municípios de Santo André, São Bernardo do Campo e São Caetano do Sul. Revista DAE. São Paulo, n. 32, pp. 57-78.

PIERSON, P. (2004). Politics in time: history, institutions, and social analysis. Princeton, Princeton University Press.

PONTES, L. A. de L. (1973). Novo sistema tarifário da SAEC. Revista DAE. São Paulo, n. 82, pp. 11-25. 
REZENDE, S. C.; HELLER, L. (2008). Saneamento no Brasil: políticas e interfaces. Belo Horizonte, Ed. UFMG.

SABESP - Companhia de Saneamento Básico do Estado de São Paulo (2019). Relatório anual Securities and Exchange Commission dos Estados Unidos da América, referente ao exercício social findo em 31 de dezembro de 2018. São Paulo.

SACHS, A. C. (1982). Saneamento Básico e o evolver de suas organizações em São Paulo. Revista de Administração de Empresas. Rio de Janeiro, v. 22, n. 1, pp. 35-42.

SANTOS, M. (2009). A urbanização brasileira. São Paulo, Edusp.

SCHMIDT, V. A. (2010). Taking ideas and discourse seriously: explaining change through discursive institutionalism as the fourth 'new institutionalism'. European Political Science Review. v. 2, n. 1, pp. 1-25.

SOUZA, C. (1981). Metropolização brasileira: uma análise e um estudo de caso. Dissertação de mestrado. São Paulo, Escola Brasileira de Administração Pública.

(2002). Brazil: The prospects of a center-constraining federation in a fragmented polity. Publius: The Journal of Federalism. Oxford, University Press, v. 32, n. 2, pp. 23-48.

(2003). Regiões metropolitanas: condicionantes do regime político. Lua Nova. São Paulo, v. 59, n. 2, pp. $137-158$

STEINMO, S.; THELEN, K.; LONGSTRETH, F. (eds.) (1992). Structuring politics: historical institutionalism in comparative politics. Cambridge, Cambridge University Press.

STF - Supremo Tribunal Federal (2020). Ação Direta de Inconstitucionalidade 6492, ajuizada pelo Partido Democrático Trabalhista. Ação Direta de Inconstitucionalidade apensada 6536, ajuizada pelo Partido Comunista do Brasil e Partido Socialismo e Liberdade. Brasília: STF. Disponível em: <portal.stf.jus.br>. Acesso em: 3 maio 2021.

STREECK, W.; THELEN, K. (2005). "Introduction: Institutional Change in Advanced Political Economies". In: STREECK, W.; THELEN, K. (eds.). Beyond continuity: institutional change in advanced political economies. Oxford, Oxford University Press, pp. 1-39.

SWYNGEDOUW, E. (2013). "Águas revoltas: a economia política dos serviços públicos essenciais". In: HELLER, L.; CASTRO, J. E. Política pública e gestão de serviços de saneamento. Belo Horizonte, UFMG, pp. 76-97.

THELEN, K. (2000). Timing and Temporality in the Analysis of Institutional Evolution and Change. Studies in American Political Development, n. 14, pp. 101-108.

WELSH, L. W.; ENDTER-WADA, J. (2017). Piping water from rural counties to fuel growth in Las Vegas, Nevada: Water transfer risks in the arid USA West. Water Alternatives, v. 10, n. 2, pp. 420-436.

ZULIANI, G. (2019). Relatório do projeto de lei n. 3.261, de 2019, atualiza o marco legal do saneamento básico e altera a lei n. 11.445/2007. Brasília. Disponível em: http://bit.do/fiBT7. Acesso em: 26 nov 2019.

Texto recebido em 26/nov/2019

Texto aprovado em 29/maio/2020 